\title{
Optic Neuritis Caused by Interferon-Beta Administration
}

\author{
Hirohisa Okuma ${ }^{1}$, Yoshiaki Kawamura ${ }^{2}$, Yuko Ohnuki ${ }^{1}$ and Shigeharu Takagi ${ }^{3}$
}

Key words: optic neuritis, interferon-beta

(Inter Med 47: 1759, 2008)

(DOI: 10.2169/internalmedicine.47.1401)
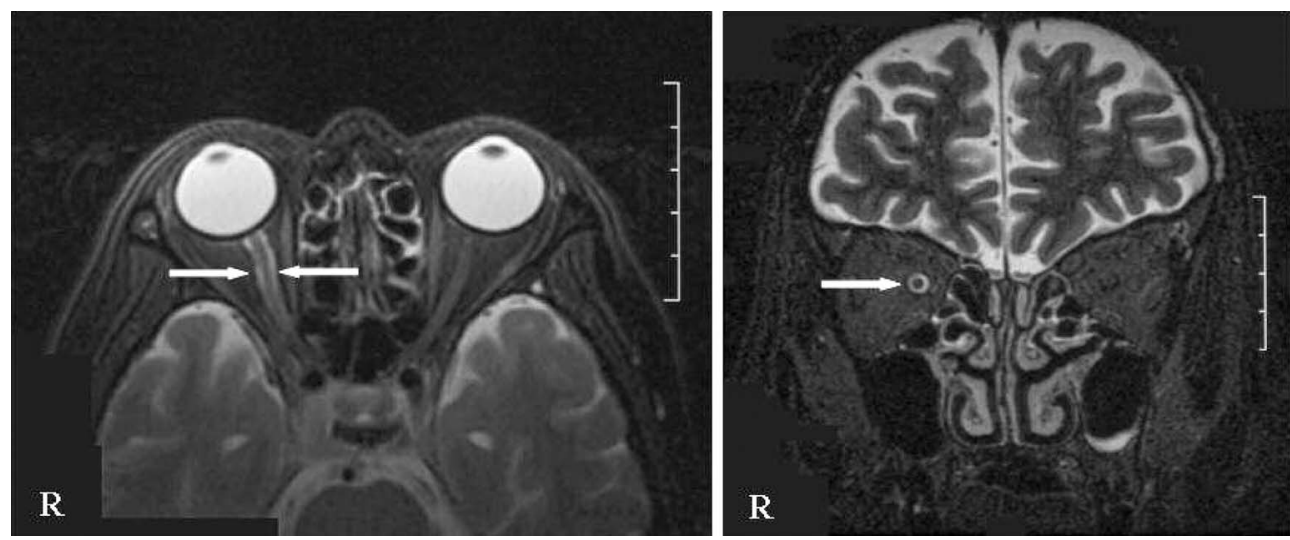

Picture 1. Head T2-weighted MR images. Coronal section, right; sagittal sections left. High intensity area around the right optic nerve is indicated with an arrow.

A 70-year-old man was diagnosed with left kidney cancer and treated with interferon-beta (interferon- $\beta$ ). He noted decreased visual acuity in the right eye on the third day after the start of interferon- $\beta$ administration. Visual acuity and discrimination function decreased and he almost lost sight in the eye. The cerebrospinal fluid findings were normal, and cerebrospinal fluid cytodiagnosis gave no indication of malignancy. Head MRI revealed high intensity in the area surrounding the right optic nerve, and a diagnosis of right optic neuritis induced by interferon- $\beta$ was made (Picture 1 ).
Interferon- $\beta$ was discontinued, and steroid pulse therapy on the following day resulted in visual improvement. Because interferon- $\beta$ can not pass through the blood brain barrier, it can not directly affect vision; we speculate that a pathological immune response may have been induced.

It is known that interferon- $\beta$ can cause retinopathy, such as retinal hemorrhage or soft vitiligo, but to date there has been no previous report of optic neuritis, or of abnormal imaging findings of the optic nerve environment following interferon treatment.

\footnotetext{
${ }^{1}$ Department of Neurology, Tokai University Tokyo Hospital, Tokyo, ${ }^{2}$ Department of Urology, Tokai University Tokyo Hospital, Tokyo and ${ }^{3}$ Department of Neurology, Tokai University School of Medicine, Tokyo

Received for publication June 10, 2008; Accepted for publication June 23, 2008

Correspondence to Dr. Hirohisa Okuma, ookuma@tok.u-tokai.ac.jp

(C) 2008 The Japanese Society of Internal Medicine Journal Website: http://www.naika.or.jp/imindex.html
} 